This item was submitted to Loughborough's Research Repository by the author.

Items in Figshare are protected by copyright, with all rights reserved, unless otherwise indicated.

\title{
A study of changes to specific absorption rates in the human eye close to perfectly conducting spectacles within the radio frequency range 1.5 to 3.0 $\mathrm{GHz}$
}

\section{PLEASE CITE THE PUBLISHED VERSION}

https://doi.org/10.1109/TAP.2004.836417

PUBLISHER

(C) IEEE

LICENCE

CC BY-NC-ND 4.0

\section{REPOSITORY RECORD}

Whittow, W.G., and R.M. Edwards. 2019. "A Study of Changes to Specific Absorption Rates in the Human Eye Close to Perfectly Conducting Spectacles Within the Radio Frequency Range 1.5 to $3.0 \mathrm{Ghz"}$. figshare. https://hdl.handle.net/2134/2902. 
This item was submitted to Loughborough's Institutional Repository by the author and is made available under the following Creative Commons Licence conditions.

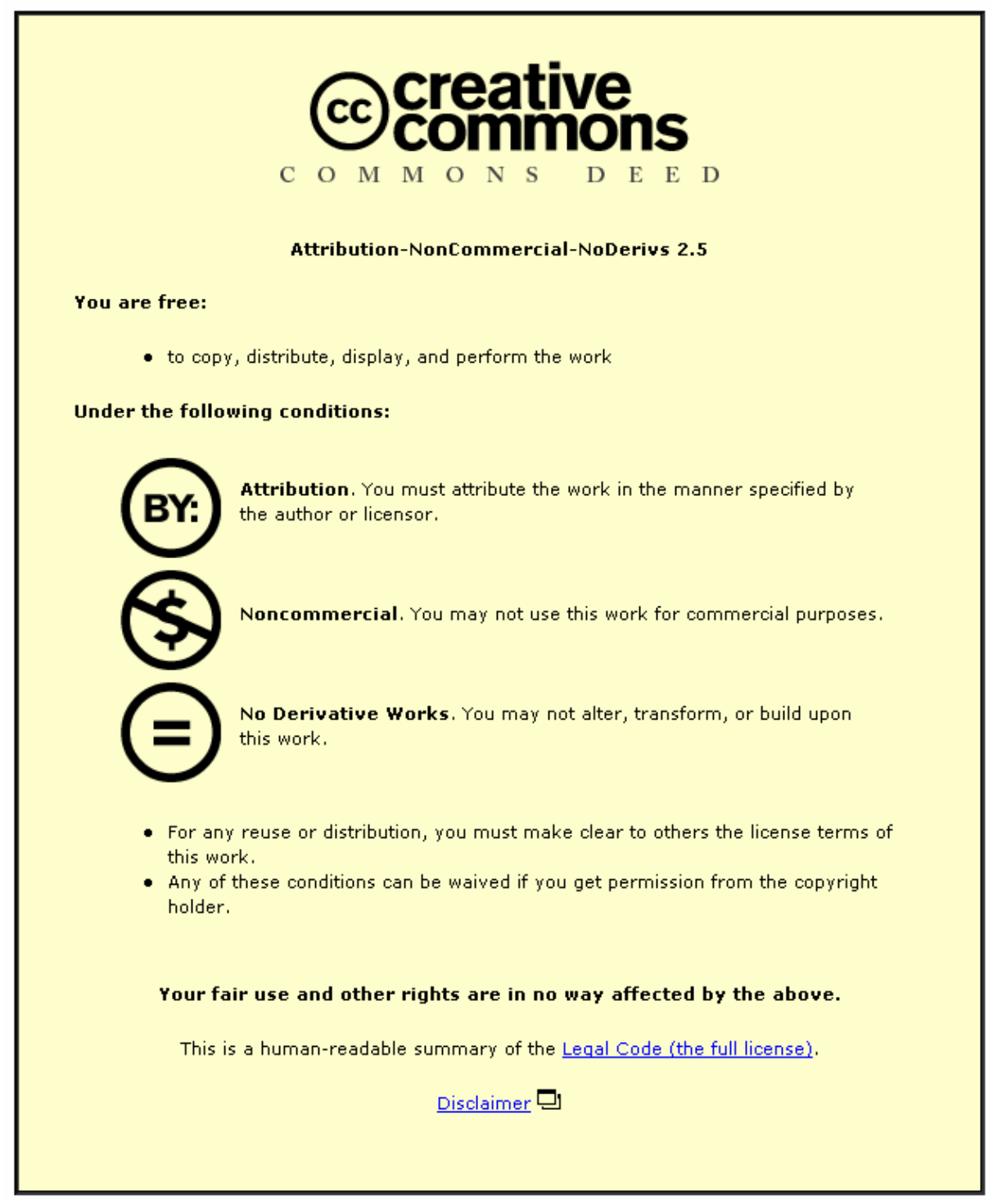

For the full text of this licence, please go to: http://creativecommons.org/licenses/by-nc-nd/2.5/ 


\section{A Study of Changes to Specific Absorption Rates in the Human Eye Close to Perfectly Conducting Spectacles Within the Radio Frequency Range 1.5 to $3.0 \mathrm{GHz}$}

Will G. Whittow and Rob M. Edwards, Member, IEEE

\begin{abstract}
This paper investigates relative changes in specific absorption rates due to perturbing metallic spectacles in proximity to the face. A representative electrical property biological matter model with 25 distinct tissue types based on magnetic resonance imaging data is used with the finite-difference time-domain method. Both plane wave and dipole stimuli are investigated and are used to represent an excitation from the front of the head. The frequency range investigated is 1.5 to $3.0 \mathrm{GHz}$. Results show that metallic spectacles may significantly alter SAR level distributions within the head. Specific attention is given to energy interactions with the eyes. Results are given for several common spectacle frame shapes.
\end{abstract}

Index Terms-Eye, finite-difference time-domain (FDTD), metallic spectacles, specific absorption rate (SAR).

\section{INTRODUCTION}

$\mathbf{R}$ ESEARCH INTO interactions between biological material and the energy generated by personal communications devices is currently topical. This paper investigates the field perturbation effects due to thin wire spectacles of various common shapes with simple slab lenses with a $\mathrm{CW}$ source positioned in front of the head. A rigorous finite-difference time-domain (FDTD) model is used. In previous works [1]-[3] it has been demonstrated that metallic spectacles can alter the specific absorption rate in the head and in particularly in the eyes. In recent years some work has been written up regarding mobile phones positioned near the ear [4]-[7]. The head has also been irradiated from in front of the eye using realistic mobile phone models [6]-[8]. This is topical as such hand held devices held to the front of and away from the head may soon become popular. Dimbylow and Hirata have illuminated the head with a plane wave from the front [9], [10] and have previously found resonance in the eyes within typical cellular spectra. Bernardi [11] considered the eyes to be particularly sensitive organs due to their proximity to the surface of the head and the relatively low levels of blood flow when compared to other regions of

Manuscript received June 11, 2003; revised February 2, 2004. This work was supported in part by the Engineering and Physical Sciences Research Council (EPSRC), U.K.

The authors were with the Electronic and Electrical Engineering Department, The University of Sheffield, Sheffield, U.K. They are now with Longhborough University, Leicestershire LE11 3TU, U.K. (e-mail: R.M.Edwards@lboro.ac.uk).

Digital Object Identifier 10.1109/TAP.2004.836417 the body. Dimbylow [6] also stresses the vulnerability of the eyes as they have a tendency to accumulate damage and cellular debris. In the same area Cooper [12], modeled a geometric head, and Bernardi [13] investigated an anatomical head, irradiated by simple dipoles positioned near metallic walls. Both found that metallic walls could increase the power absorbed in the head. Similarly Cooper [14] considered metal implantations inside the head and found that they increased the specific absorption rate (SAR) in the surrounding region. These papers show that metal objects close to biological matter may increase SAR in that matter. Spectacles have received limited attention in the literature, however, Bernardi [11] did model a glass lens in two dimensions. Troulis [15] used the FDTD method to briefly examine thin metallic spectacles on a heterogeneous phantom with a resolution of $5 \mathrm{~mm}$. The excitation used was a monopole on a metallic box positioned at the side of the head. The paper showed that metallic spectacles can re-distribute the energy, produced by the cell phone's antenna, causing the efficiency to drop and the peak SAR to increase. Griffin [1] performed measurements with a phantom and metallic spectacles and showed that spectacles can increase or decrease the level of radiation near the eyes by up to $20 \mathrm{~dB}$ due to shielding, enhancement and depolarization effects. Anderson also performed measurements with a phantom wearing metallic spectacles. With phones operating at $835 \mathrm{MHz}$ held by the ear, the SAR in the eye closest to the phone was found to increase by up to $29 \%$.

The novel area of head, thin wire spectacle, and RF energy interaction from in front of the eyes will now be considered in greater detail.

\section{DESCRIPTION OF MODEL}

An independent three dimensional (3-D) FDTD code has been written; see Taflove [16] for an excellent reference. Perfectly matched layers (PML), with geometric grading [17], absorbing boundary conditions are used to terminate the grid. The PML is eight-cells thick and is positioned ten cells from the head. The FDTD grid size was $174 \times 140 \times 140$ cells in the $X, Y$, and $Z$ dimensions.

\section{A. Plane Wave Source Irradiation}

A plane wave is injected into the grid using the total field/scattered field approach [16]. This produces a $Z$ polarized plane wave propagating in the $X$ direction (from the nose to the rear 


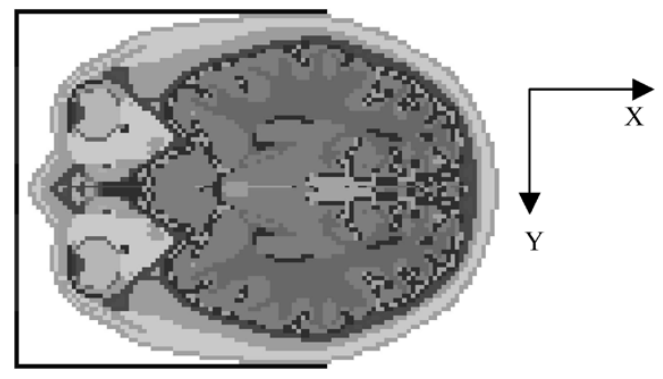

Fig. 1. Cross section through the eyes of the heterogeneous head of $2 \mathrm{~mm}$ resolution. Spectacles have been added $2.6 \mathrm{~cm}$ in front of the eye.

of the head). See Fig. 1 for orientation of the axes. The power density used was $50 \mathrm{~W} / \mathrm{m}^{2}$, the maximum permissible exposure limit for controlled environments [10].

\section{B. Dipole Wave Source Irradiation}

For comparison a simple half-wavelength dipole model [16] has also been included in this paper. The dipole is vertically polarized fed at its center with a sinusoidal $\mathrm{CW}$ source. The tangential E-field components are set to zero along the length of the dipole.

\section{The Head Model}

A head matrix provided by Brooks Air force [18] was used. The head, which is based on MRI data, is that of an adult male and has 25 tissue types. The data is available at both 1 and $2 \mathrm{~mm}$ resolutions.

Fig. 1 below shows a cross section of the $2 \mathrm{~mm}$ head including the spectacles through the center of the eye. The layer of fat, muscle, and skin in front of the eye can be seen which make up the eyelids. It should be noted that the Brooks head has closed eyelids and the results in this paper with the $2 \mathrm{~mm}$ model are calculated with the eyelids closed. Hirata [10] showed that opening the eyelid increased the average SAR in the eye by $15 \%$ at $5.0 \mathrm{GHz}$. Results in Section IV-F of are calculated with a more detailed $1 \mathrm{~mm}$ resolution head. The results with the $1 \mathrm{~mm}$ head in Section IV-F are calculated with the eyelids manually removed. Skin, fat and muscle tissues were replaced with air, in an elliptical region $30 \mathrm{~mm}$ by $12 \mathrm{~mm}$ in front of the eye.

The size of the Yee cell was equal to the resolution of the heads used, i.e., $2 \mathrm{~mm}$ in Sections IV-A-E and $1 \mathrm{~mm}$ in Section IV-F. The lowest number of cells per wavelength was always greater than six, and reasonable results have been obtained with only four [9]. Although the Brooks head is not exactly symmetric, a line of symmetry, in the $Y$ direction, has been included in this model to save memory and computational time. This was achieved by replacing the mid-plane of the grid with a magnetic wall [10], and thus assuming the other half of the head is identical. Note, Figs. 1 and 2 show the whole head to aid visualization of the problem. The use of symmetry was found to have negligible effect on SAR results in the eye.

The dielectric properties are calculated with aid of the 4-ColeCole extrapolation [19] and are frequency dependant. At the interface between two materials, the average values of conductivity and permittivity are used. The densities of the different materials are the same as used by Mason [20].
SAR is the standard criteria to measure the amount of electromagnetic energy absorbed in the body and is calculated as follows:

$$
\mathrm{SAR}=\frac{\sigma|E|^{2}}{\rho}(\mathrm{W} / \mathrm{kg})
$$

where $\mathrm{E}$ is the root mean square of the electric field components, $\rho$ is the density of the material in $\mathrm{kg} / \mathrm{m}^{3}$ and $\sigma$ is the conductivity in $\mathrm{S} / \mathrm{m}$. The SAR is calculated with the 12 -field approach as used by Caputa [21].

\section{Modeling THE SPECTACLES}

The spectacles were modeled using metallic Yee cells, by setting the conductivity of the cells equal to the conductivity of copper. Nikita [22] and Bernardi [13] both used this technique to model metal shapes. Four arbitrary but representative frame types were researched: square (external dimensions of $36 \mathrm{~mm} \times 36 \mathrm{~mm}$ in $Y$ and $Z$ axis), circular ( $44 \mathrm{~mm} \times 44 \mathrm{~mm}$ ), rectangular $(48 \mathrm{~mm} \times 28 \mathrm{~mm})$, and elliptical $(48 \mathrm{~mm} \times 28 \mathrm{~mm})$. See Fig. 2 for orientation and geometry.

In each case the center of the lens was positioned at the center of the eye in the $Y-Z$ plane, and $2.6 \mathrm{~cm}$ in front of the cornea. The cells between the frames were assigned a relative permittivity of 2.56; thereby including realistic Perspex lens 2-mm thick. In addition to these basic geometric shapes, a nosepiece and a strut to the arm were included-see Fig. 2. Care was taken to ensure that the frames did not lie inside the head or touch the skin. Spectacle arms were modeled as a line of single metallic Yee cells, extending $14 \mathrm{~cm}$ in the $X$ direction, touching the head above the ear.

The FDTD, code including the PML absorbing boundary conditions, has been validated with results by Meier [23]. Fig. 3 shows the SAR as a function of distance into a three layered sphere excited by a $0.45 \lambda$ dipole at $1.8 \mathrm{GHz}$. The head had a diameter of $200 \mathrm{~mm}$, composed of skin (5-mm thick), skull (10-mm thick), and brain. The head was positioned $15 \mathrm{~mm}$ away from the dipole. Note, the cell size for this validation was increased to $2.5 \mathrm{~mm}$ so that multiples of $5 \mathrm{~mm}$ could be accurately modeled.

The results show good agreement. In previous works [3] the average SAR in an anatomical head excited with $E z$ and $E y$ polarized plane waves as a function of frequency also showed good agreement with Hirata [10].

\section{RESULTS}

To examine the effect of adding metallic spectacles, three metrics were investigated; the maximum local SAR in a single cell, the $\mathrm{SAR}_{1 \mathrm{G}}$ averaged over one gram and the average $\mathrm{SAR}$ in the eye. The results in Sections IV-A-D have been made with a $50 \mathrm{~W} / \mathrm{m}^{2} E z$ polarized plane wave traveling toward the back of the head.

\section{A. Maximum Local SAR in a Yee Cell}

The maximum local SAR in any one Yee cell in the head with and without spectacles was investigated over the frequency range of 1.5 to $3.0 \mathrm{GHz}$. The addition of metal spectacles generally gives an increased maximum local SAR over this 


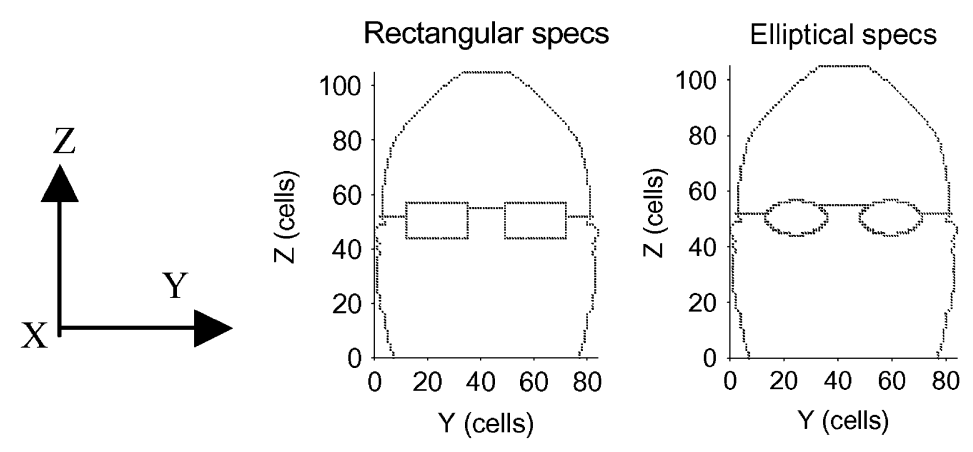

Fig. 2. Orientation and coordinate system used. Rectangular and elliptical spectacles are shown relative to the outline of the head.

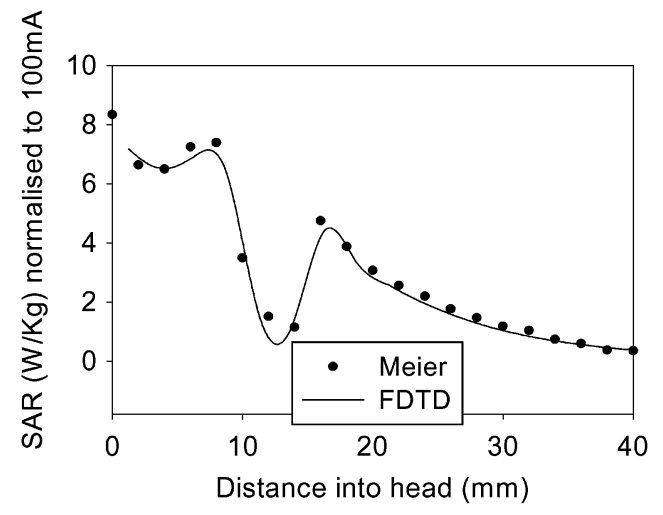

Fig. 3. SAR into a 3 layered spherical head excited by a dipole at $1.8 \mathrm{GHz}$, compared with Meier.

frequency range. The four shapes of spectacle, square, circular, elliptical, and rectangular, give similar effects in local SAR but this effect is shifted in frequency. The maximum local SAR in any one Yee cell in the head is approximately doubled with rectangular frames at $2.1 \mathrm{GHz}$ and also with elliptical frames at $2.6 \mathrm{GHz}$. All four frames considered also marginally decrease the maximum local SAR in any one Yee cell in the head at several specific frequencies. In terms of location it was found that the position of the maximum SAR shifts from the skin at the front of the nose when no spectacles are present, to the skin close to the metal edges of the spectacles, either on the side of the nose or on the side of the head next to the metallic arms.

\section{B. Maximum SAR in the Eye Averaged Over $1 \mathrm{~g}$}

The maximum $\mathrm{SAR}_{1 \mathrm{G}}$, is comparable with the ANSI/IEEE standards of $8.0 \mathrm{~W} / \mathrm{kg}$ for controlled environments [24]. The $\mathrm{SAR}_{1 \mathrm{G}}$ is calculated according to Caputa [21] using only eye tissues and no air is included in the $1 \mathrm{~g}$ cube. Metallic spectacles increase the $\mathrm{SAR}_{1 \mathrm{G}}$ below $2.2 \mathrm{GHz}$ and decrease it above this frequency. Elliptical spectacles again cause a peak at a slightly higher frequency. The $\mathrm{SAR}_{1 \mathrm{G}}$ exhibits similar behavior to the values of average SAR in the eye in Fig. 4, except the amplitude of the SAR averaged over the eye is very closely equal to half $\mathrm{SAR}_{1 \mathrm{G}}$. Hence the graph of $\mathrm{SAR}_{1 \mathrm{G}}$ in the eye is not shown to save space.

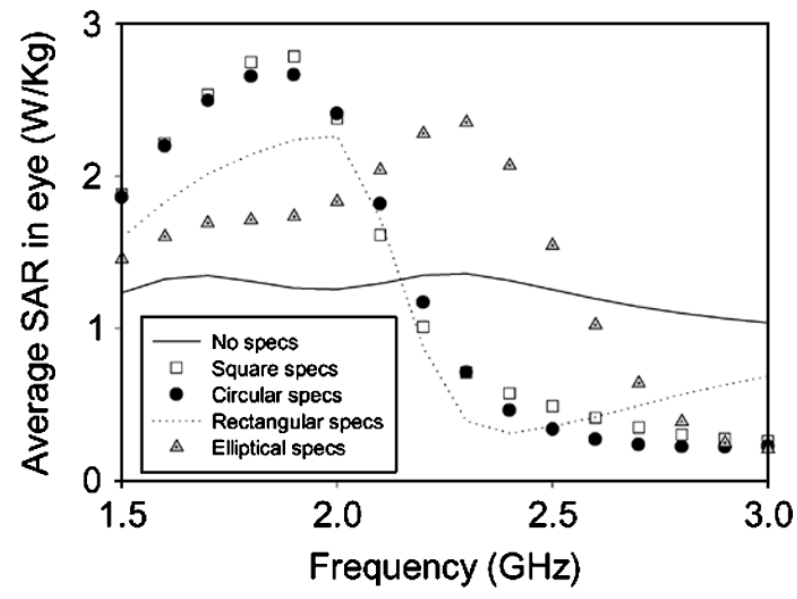

Fig. 4. SAR averaged over eye with and without spectacles.

\section{Average SAR in the Eye}

The eye in this model has a mass of approximately $8.37 \mathrm{~g}$ and is comparable to the ICNIRP safety standard of $10 \mathrm{~W} / \mathrm{kg}$ averaged over $10 \mathrm{~g}$ for controlled environments [25].

The maximum effect of metallic spectacles is with square frames at $1.9 \mathrm{GHz}$, which result in an increase of approximately $120 \%$ compared to no spectacles. However, adding spectacles can also decrease the average SAR in the eye for the spectra considered here, particularly at higher frequencies. Elliptical spectacles at $3.0 \mathrm{GHz}$ reduce the power absorbed in the eye by approximately $80 \%$.

All four frames examined increase or decrease (depending on the frequency) the power absorbed in the whole head by approximately $10 \%$. The maximum increase in the power absorbed in the head is with square frames at $1.9 \mathrm{GHz}$, which results in an increase of approximately $13 \%$.

\section{Using a Pareto Ranked Genetic Algorithm (GA) With an Ez Polarized Plane Wave Stimulus}

A GA was used to search for the maximum effects of adding metallic spectacles at $1.8 \mathrm{GHz}$. The objective of the GA was to provide the complete range of SAR that are produced in the eye with the many shapes and sizes of real spectacles. The algorithm used was that described in [26]. The search algorithm had two objectives; the average SAR in the eye and the maximum SAR averaged over $1 \mathrm{~g}$ of the eye. 
Seven different genes were varied to create chromosomes to represent various kinds of spectacles; the genes were: the distance from the front of the eye to the frames, the width of the frames, the height of the frames, the material of the lens (glass or Perspex), the thickness of the lens, the shape of the frames (rectangular or elliptical), and the length of the strut from the edge of the frame to the arm. The arms were then tapered by stair-casing the metallic Yee cells to fit the head, touching the sides of the head.

The GA found a configuration of spectacles with an average SAR in the eye of $3.399 \mathrm{~W} / \mathrm{kg}$. This represents an increase of $159 \%$ compared to $1.311 \mathrm{~W} / \mathrm{kg}$ - the average SAR in the eye with no spectacles present. The same configuration of spectacles increased the maximum SAR averaged over $1 \mathrm{~g}$ from 2.639 to $7.286 \mathrm{~W} / \mathrm{kg}$, an increase of $176 \%$. The spectacles that gave the biggest increase in the SAR in the eye were positioned $26 \mathrm{~mm}$ in front of the eye. The frames were rectangular with a width of $36 \mathrm{~mm}$ and a height of $38 \mathrm{~mm}$. The lens was 4-mm thick and made of glass. The strut length was $18 \mathrm{~mm}$.

The GA also produced configurations of spectacles that reduced the SAR in the eye. The lowest result found for the average SAR in the eye was $0.469 \mathrm{~W} / \mathrm{kg}$, a decrease of $64 \%$ compared to without spectacles. The $\mathrm{SAR}_{1 \mathrm{G}}$ was $0.994 \mathrm{~W} / \mathrm{kg}$. The spectacles were positioned $28 \mathrm{~mm}$ from the eye. The frames were rectangular, $46-\mathrm{mm}$ wide by $38-\mathrm{mm}$ high. A $6-\mathrm{mm}$ glass lens was used and the strut length was $6 \mathrm{~mm}$.

Generally the average SAR in the eye was mainly influenced by the size of the frames, with high narrow spectacles likely to give the highest results. Rectangular frames gave higher SAR in the eye than elliptical frames at $1.8 \mathrm{GHz}$. Increasing the thickness of the lens, and changing the material to glass, which has a higher permittivity, increased the average SAR in the eye by up to $15 \%$. Bernardi [11] showed that a glass lens can act as adaptor increasing the SAR in the eye. Varying the total width of the spectacles changed the SAR in the eye by up to $2 \%$.

One hundred pairs of spectacles were produced with random parameters governing the seven parameters to allow a statistical analysis. All of these spectacles increased the average SAR in the eye by $14 \%$ to $143 \%$. The average increase was $56 \%$. Rectangular frames had a slightly larger effect, increasing the SAR in the eye by $62 \%$ compared to $49 \%$ with elliptical frames. One hundred random spectacles were also modeled in the same way at both 2.4 and $3.0 \mathrm{GHz}$. At $2.4 \mathrm{GHz}$, the SAR in the eye was increased by $51 \%$ on average and at $3.0 \mathrm{GHz}$ the spectacles decreased the SAR in the eye by $11 \%$.

To investigate the effects of the source at $1.8 \mathrm{GHz}$, the $E z$ plane wave excitation was replaced by $Z$ directed dipole positioned $8 \mathrm{~cm}$ in front of the nose. The dipole was given an input power of $0.6 \mathrm{~W}$ to allow the amplitude to be comparable with a realistic source. Fig. 5 shows the average SAR in the eye for the $Z$ directed dipole with the spectacles that gave the highest SAR in the eye with $E z$ polarized plane wave. It should be noted that the results from the plane wave excitation have been scaled by $1 / 15$ so the amplitudes are comparable. The scaled results are very similar for the two excitations over the frequency range 1.5 to $3.0 \mathrm{GHz}$. The same spectacles give an increase in the average SAR in the eye of approximately $160 \%$ at $1.8 \mathrm{GHz}$ and a decrease of approximately $80 \%$ at $2.4 \mathrm{GHz}$. The results show that

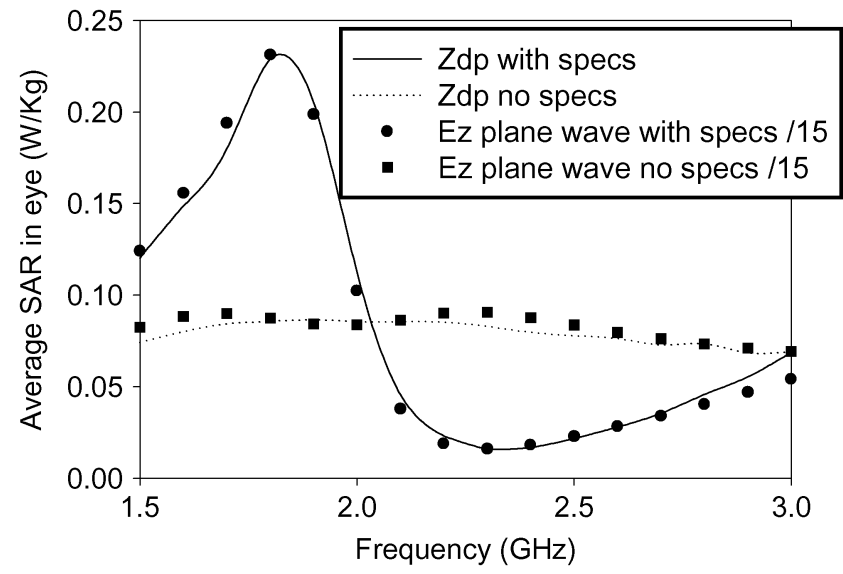

Fig. 5. Using the spectacles, that gave the highest average SAR in the eye at $1.8 \mathrm{GHz}$ for the $E z$ plane wave, with two different excitations: a $50 \mathrm{~W} / \mathrm{m}^{2} E z$ plane wave and a $0.6 \mathrm{~W} Z$ directed dipole. Note, the plane wave results have been scaled by a factor of $1 / 15$.

the effect of the spectacles is not dependent on the excitation as long as the results are scaled accordingly.

\section{E. Using the GA With an Ey Polarized Plane Wave at $1.8 \mathrm{GHz}$}

In this section the head is rotated so it is excited with an $E y$ polarized plane wave from the front traveling in the $X$ direction. The power density was kept at $50 \mathrm{~W} / \mathrm{m}^{2}$. The GA was again used to search for the highest average SAR in the eye and the maximum $\mathrm{SAR}_{1 \mathrm{G}}$ in the eye, with the same parameters as outlined earlier. The GA found no spectacles that increased the SAR in the eye. The maximum average SAR in the eye found was $0.836 \mathrm{~W} / \mathrm{kg}$, which corresponds to a decrease of $45 \%$, compared to the same excitation with a head without spectacles. This pair of spectacles were positioned $32 \mathrm{~mm}$ in front of the eye, had a rectangular frame of $48 \mathrm{~mm}$ by $38 \mathrm{~mm}$, a $6-\mathrm{mm}$ glass lens, and the strut length was $16 \mathrm{~mm}$. Varying the properties of the spectacles was found to be less significant than with an $E z$ polarized plane wave. Varying the total width of the spectacles caused variations in the average SAR in the eye by $10 \%$, compared to $2 \%$ with an $E z$ plane wave.

Fig. 6 shows the spectacles outlined in the paragraph above over the frequency range 1.5 to $3.0 \mathrm{GHz}$. The same spectacles have also been modeled with a $0.6-\mathrm{W} Y$ directed $0.45 \lambda$ dipole, $8 \mathrm{~cm}$ in front of the nose. These results are also included and to allow direct comparison the plane wave results have been scaled by a factor of $1 / 15$. Again the $Y$ orientated dipole and Ey plane wave excitations give similar results with and without spectacles across the frequency range considered, if the results are scaled. At all frequencies considered this pair of spectacles reduced the average SAR in the eye. Although the graph indicates that metallic spectacles could increase the SAR in the eye above $3.0 \mathrm{GHz}$ if the excitation is polarized in the $Y$ direction.

\section{F. Varying the Size of the Frames of Metallic Spectacles at 1.8 and $2.4 \mathrm{GHz}$}

Analysing results from the GA showed that the size and shape of the frames was the most significant factor on the SAR in the eye. This section will investigate different sizes of frames at two important communication frequencies, 1.8 and $2.4 \mathrm{GHz}$. To increase the realism of the model, a 1-mm resolution head 


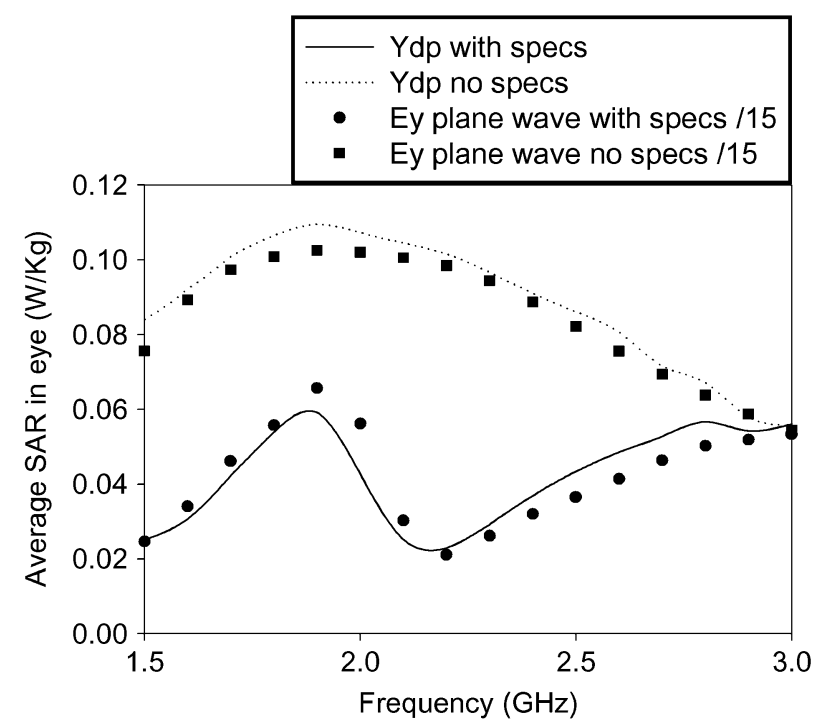

Fig. 6. SAR averaged over the whole eye across 1.5 to $3.0 \mathrm{GHz}$. Spectacles used gave highest average SAR in the eye at $1.8 \mathrm{GHz}$ with an $E y$-plane wave. Results are for two excitations: a $50-\mathrm{W} / \mathrm{m}^{2} E y$ plane wave and a $0.6-\mathrm{W} Y$ directed dipole. Note, the plane wave results have been scaled by a factor of $1 / 15$ to compare properly with the dipole.

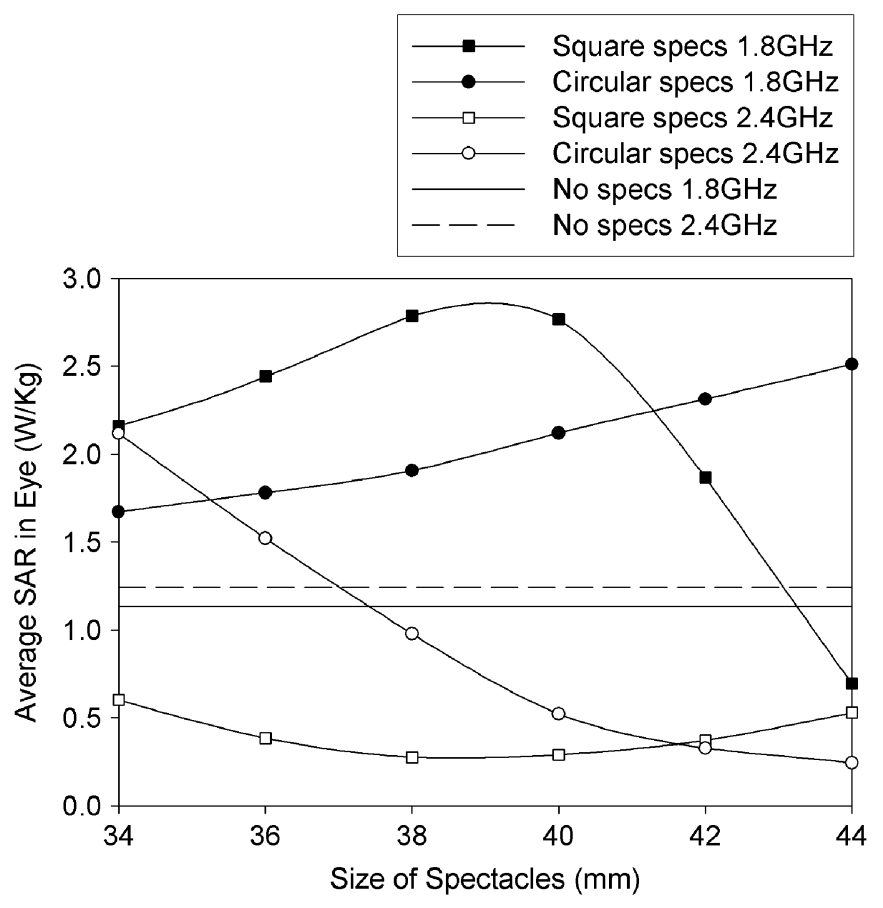

Fig. 7. SAR averaged over eye with and without spectacles at 1.8 and $2.4 \mathrm{GHz}$.

was used and the eyelids were artificially opened. The head was assumed to be symmetric and the excitation used is a $50-\mathrm{W} / \mathrm{m}^{2}$ vertically polarized plane wave. The exterior dimensions of the spectacle frames were varied from 34 to $44 \mathrm{~mm}$. A 2-mm thick Perspex lens was added and the arms were perpendicular to the frames.

The values of $\mathrm{SAR}_{1 \mathrm{G}}$ in the eye are approximately twice the average SAR in the eye shown in Fig. 7. The addition of square and circular spectacles of these sizes generally increases the SAR in the eye at $1.8 \mathrm{GHz}$ and reduces it at $2.4 \mathrm{GHz}$. This is true for all the spectacles examined except the following cases;

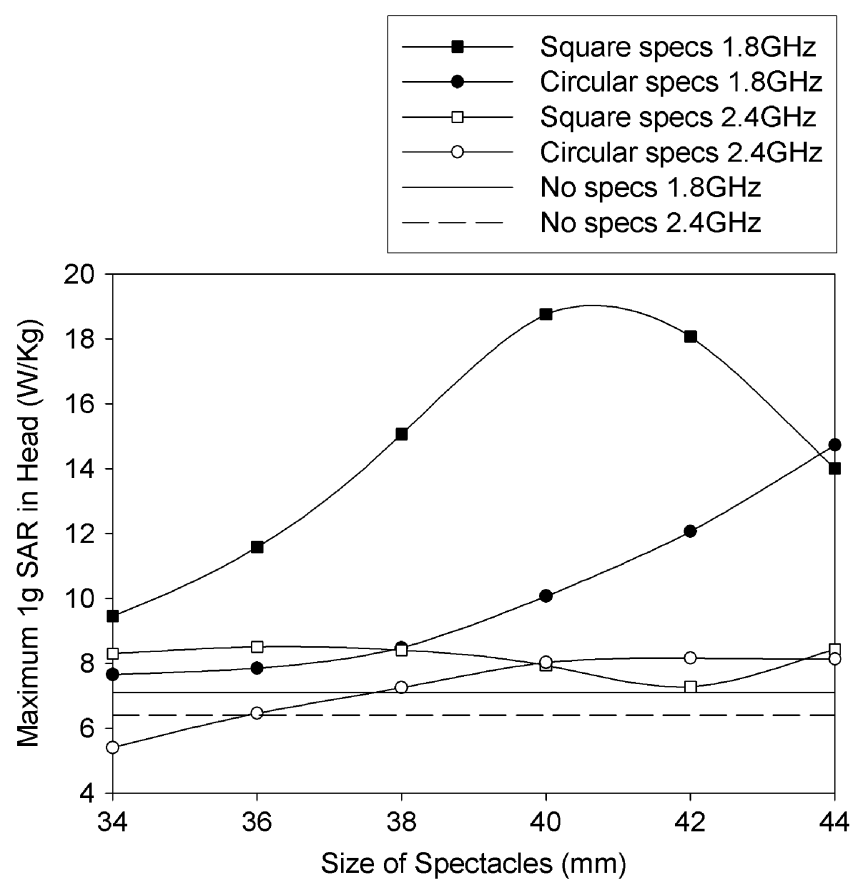

Fig. 8. Maximum SAR averaged over $1 \mathrm{~g}$ in the head at 1.8 and $2.4 \mathrm{GHz}$.

44-mm square spectacles marginally decreases the SAR in the eye at $1.8 \mathrm{GHz}$ and 34 and $36 \mathrm{~mm}$ circular spectacles increases the SAR in the eye at $2.4 \mathrm{GHz}$. The size and shape of the metallic frames has a strong influence on the SAR in the eye. At $1.8 \mathrm{GHz}$ the SAR in the eye increases as the size of circular frames increases. The SAR averaged over the eye increases by $146 \%$ in the case of $38-\mathrm{mm}$ square frames at $1.8 \mathrm{GHz}$ and decreases by $80 \%$ with the addition of $44-\mathrm{mm}$ circular spectacles at $2.4 \mathrm{GHz}$.

The $\mathrm{SAR}_{1 \mathrm{G}}$ and the $\mathrm{SAR}_{10 \mathrm{G}}$ in the head have also been investigated using all head tissues. No air is included in the averaging cube. As only half the head has been considered the maximum $\mathrm{SAR}_{1 \mathrm{G}}$ and $\mathrm{SAR}_{10 \mathrm{G}}$ in the head have been calculated assuming that the head is symmetric. Again $\mathrm{SAR}_{10 \mathrm{G}}$ is approximately half the value of $\mathrm{SAR}_{1 \mathrm{G}}$, and to save space only results of $\mathrm{SAR}_{1 \mathrm{G}}$ in the head are included-see Fig. 8.

The addition of metallic spectacles again has a significant influence on the maximum $\mathrm{SAR}_{1 \mathrm{G}}$ in the head. The 34-mm circular spectacles decrease the $\mathrm{SAR}_{1 \mathrm{G}}$ in the head at $2.4 \mathrm{GHz}$, however, all the other sizes of spectacles considered; increase the $\mathrm{SAR}_{1 \mathrm{G}}$ in the head. The effect of spectacles is greater at $1.8 \mathrm{GHz}$ than $2.4 \mathrm{GHz}$. The largest increase in the $\mathrm{SAR}_{1 \mathrm{G}}$, in the head at $1.8 \mathrm{GHz}$, is with $40-\mathrm{mm}$ square spectacles which give an increase of $164 \%$. The same spectacles increase the $\mathrm{SAR}_{10 \mathrm{G}}$ by $195 \%$. At $2.4 \mathrm{GHz}$, the effects are less dependent on spectacle size. The largest increase is with 44-mm square frames which increase the $\mathrm{SAR}_{1 \mathrm{G}}$ by $32 \%$. The $34-\mathrm{mm}$ circular spectacles reduce the $\mathrm{SAR}_{1 \mathrm{G}}$ in the head by $16 \%$.

\section{CONCLUSION}

The results presented in this paper show that metallic spectacles can substantially change the SAR in the head, over the frequency range 1.5 to $3.0 \mathrm{GHz}$, when the excitation is from the front. The SAR averaged over the eye has been shown to increase by up to $160 \%$ and decrease by up to $80 \%$, depending 
on the specific spectacles and the frequency of excitation. Statistical analysis shows that an average pair of spectacles can be expected to increase the SAR in the eye by about $50 \%$ at 1.8 and $2.4 \mathrm{GHz}$ and marginally decrease it at $3.0 \mathrm{GHz}$. Increases of around $10 \%$ are possible for the entire head. The differences between different spectacles are mostly due to the size and shape of the frames, and the lens and arm are less important. A genetic algorithm has been used to find the spectacles that gave the highest SAR in the eye. Substantial increases and decreases in the power absorbed in the eyes have been shown. The addition of spectacles was found to decrease the SAR in the eye for both a horizontally polarized plane wave and a horizontally polarized dipole. A $Z$-polarized source approximately quadruples the energy absorbed in the eye when metallic spectacles are added compared to a $Y$ polarized source. A dipole excitation gives similar results to the plane wave excitation, once the results have been scaled, showing that the effects of spectacles are more dependent on the size and shape of the frames, the frequency and the polarization than the specific source. Future work will investigate the effects of spectacles with more realistic sources.

\section{REFERENCES}

[1] D. W. Griffin, "A microwave antenna method of measuring the effect of metal-framed spectacles on microwaves near the eye," in Proc. Antennas and Propagation Soc. Int. Symp., vol. 21, 1983, pp. 253-256.

[2] V. Anderson and K. H. Joyner, "Specific absorption rate levels measured in a phantom head exposed to radiofrequency transmissions from analog hand-held mobile phones," Bioelectromagn., vol. 16, no. 1, pp. 60-69, 1995.

[3] W. G. Whittow, R. M. Edwards, and G. G. Cook, "A study of changes to specific absorption rates in the human eye close to perfectly conducting spectacles within the radio frequency range 1.5 to $3.0 \mathrm{GHz}$," in Proc. 12th Int. Conf. Antennas Propagation, Exeter, U.K., Mar. 31, 2003, pp. 300-303.

[4] A. D. Tinniswood, C. M. Furse, and O. P. Gandhi, "Computations of SAR distributions for two anatomically based models of the human head using CAD files of commercial telephones and the parallelized FDTD code," IEEE Trans. Antennas Propagat., vol. 46, pp. 829-833, June 1998.

[5] O. Gandhi, G. Lazzi, and C. M. Furse, "Electromagnetic absorption in the human head and neck for mobile telephones at 835 and 1900 MHz," IEEE Trans. Microwave Theory Technol., vol. 44, no. 10, pp. 1884-1897, Oct. 1996.

[6] P. J. Dimbylow and S. M. Mann, "Sar calculations in an anatomically realistic model of the head for mobile communication transceivers at $900-\mathrm{MHz}$ and 1.8-GHz," Phys. Med. Biol., vol. 39, no. 10, pp. 1537-1553, 1994.

[7] P. Wainwright, "Thermal effects of radiation from cellular telephones," Phys. Med. Biol., vol. 45, pp. 2363-2372, 2000.

[8] L. Martens, J. Demoerloose, D. Dezutter, J. Depoorter, and C. Dewagter, "Calculation of the electromagnetic-fields induced in the head of an operator of a cordless telephone," Radio Sci., vol. 30, no. 1, pp. 283-290, 1995.

[9] P. J. Dimbylow and O. P. Gandhi, "Finite-difference time-domain calculations of SAR in a realistic heterogeneous model of the head for plane-wave exposure from $600 \mathrm{MHz}$ to $3 \mathrm{GHz}$," Phys. Med. Biol., vol. 36, no. 8, pp. 1075-1089, 1991.

[10] A. Hirata, S. Matsuyama, and T. Shiozawa, "Temperature rises in the human eye exposed to EM waves in the frequency range 0.6-6 GHz," IEEE Trans. Electromagn. Compat., vol. 42, no. 4, pp. 386-393, Nov. 2000.

[11] P. Bernardi, M. Cavagnaro, S. Pisa, and E. Piuzzi, "SAR distribution and temperature increase in an anatomical model of the human eye exposed to the field radiated by the user antenna in a wireless LAN," IEEE Trans. Microwave Theory Tech., vol. 46, no. 12, pp. 2074-2082, Dec. 1998.

[12] J. Cooper and V. Hombach, "The specific absorption rate in a spherical head model from a dipole with metallic walls nearby," IEEE Trans. Electromagn. Compat., vol. 40, no. 4, pp. 377-382, Nov. 1998.
[13] P. Bernardi, M. Cavagnaro, and S. Pisa, "Evaluation of the SAR distribution in the human head for cellular phones used in a partially closed environment," IEEE Trans. Electromagn. Compat., vol. 38, no. 3, pp. 357-366, Aug. 1996.

[14] J. Cooper and V. Hombach, "Increase in specific absorption rate in humans from implantations," Electron. Lett., vol. 32, no. 24, 1996.

[15] S. E. Troulis, W. G. Scanlon, and N. E. Evans, "Effect of "hands-free" leads and spectacles on SAR for a $1.8 \mathrm{GHz}$ cellular handset," in Proc. 1st Joint IEI/IEE Symp. Telecommunications Systems Research, Dublin, Ireland, Nov. 27, 2001.

[16] A. Taflove, "Computational electrodynamics," The Finite-Difference Time-Domain Method, 1995.

[17] J. P. Berenger, "A perfectly matched layer for the absorpton of electromagnetic waves," J. Computational Phys., vol. 114, pp. 185-200, 1994.

[18] Brooks Airforce Base, San Antonio, TX. [Online]. Available: ftp://starview.brooks.af.mil/EMF/dosimetry_models/

[19] S. Gabriel, R. W. Lau, and C. Gabriel, "The dielectric properties of biological materials: III Parametric models for the dielectric spectrum of tissues," Phys. Med. Biol., vol. 41, pp. 2271-2293, 1995.

[20] P. A. Mason, W. D. Hurt, T. J. Walters, J. A. D'Andrea, P. Gajsek, K. L. Ryan, D. A. Nelson, K. I. Smith, and J. M. Ziriax, "Effects of frequency, permitivity and voxel size on predicted specific absorption rate values in biological tissue during electromagnetic-field exposure," IEEE Trans. Microwave Theory Tech., vol. 48, no. 11, pp. 2050-2058, Nov. 2000.

[21] K. Caputa, M. Okoniewski, and M. A. Stuchly, "An algorithm for computations of the power deposition in human tissue," IEEE Antennas Propagat. Mag., vol. 41, no. 4, pp. 102-107, 1999.

[22] K. S. Nikita, M. Cavagnaro, P. Bernardi, N. K. Uzunoglu, S. Pisa, E. Piuzzi, J. N. Sahalos, G. I. Krikelas, J. A. Vaul, P. S. Excell, G. Cerri, S. Chiarandini, R. De Leo, and P. Russo, "A study of uncertainties in modeling antenna performance and power absorption in the head of a cellular phone user," IEEE Trans. Microwave Theory Tech., vol. 48, no. 12, pp. 2676-2685, Dec. 2000.

[23] K. Meier, V. Hombach, R. Kastle, R. Tay, and N. Kuster, "The dependence of electromagnetic energy absorption upon human-head modeling at $1800 \mathrm{MHz}$," IEEE Trans. Microwave Theory Tech., vol. 45, no. 11, pp. 2058-2062, Nov. 1997.

[24] IEEE Standard for Safety Levels with Respect to Human Exposure to Radio Frequency Fields $3 \mathrm{kHz}$ to $300 \mathrm{GHz}$, 1992. C95.1-1992, A.I.S..

[25] International Commission for Non Ionising Radiation Protection, "Guidelines for limiting exposure to time-varying electric, magnetic and electromagnetic fields (up to $300 \mathrm{GHz}$ )," Health Phys., vol. 74, pp. 494-522, 1998.

[26] R. M. Edwards and G. G. Cook, "3G tri band probe fed printed eccentric spiral antenna for nomadic wireless devices using optimal convergence for Pareto ranked genetic algorithm," in Proc. ICAP 11th Int. Conf. Antennas and Propagation, Manchester, U.K., Apr. 17, 2001.

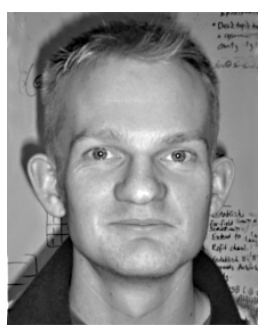

Will G. Whittow was born in Haroldwood, U.K., in 1977. He received the B.Sc. degree in physics and the Ph.D. degree in the Electronic and Electrical Engineering Department from The University of Sheffield, Sheffield, U.K., in 2000 and 2004, respectively.

$\mathrm{He}$ is currently continuing his research at Loughborough University, Leicestershire, U.K.

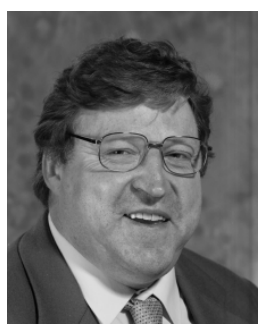

Rob M. Edwards (M'00) read in Electronic Engineering with Communications at the University of Sheffield, Sheffield, U.K., in 1996, and received the $\mathrm{Ph} . \mathrm{D}$. degree from the Department's Communications and Radar Group, in 1999.

For several years he was the Director of the Centre for Mobile Communications Research (C4MCR) at the University of Sheffield. In 2004, he joined the Centre for Mobile Communications Research (CMCR), Loughborough University, Leicestershire, U.K.

Dr. Edwards is a Member of the Institution of Electrical Engineers (IEE) London, U.K. 